\title{
Chapter 31 \\ Pituitary Adenylate Cyclase-Activating Polypeptide in the Auditory System
}

\author{
Balazs D. Fulop, Dora Reglodi, Adrienn Nemeth, and Andrea Tamas
}

\begin{abstract}
Pituitary adenylate cyclase-activating polypeptide (PACAP) is a neuropeptide with well-known neurotrophic, neuroprotective, antioxidant, and antiapoptotic effects. It also exerts protective effects in sensory organs, such as visual and olfactory system. In this review we present data regarding the localization and effects of PACAP in the auditory system. PACAP and its specific receptor (PAC1-R) are present in the organ of Corti in hair cells, supporting cells, and different nerve fibers. They are also present in the spiral ganglion showing co-localization with efferent fibers of glutamatergic and adrenergic pathways, probably directly affecting the efferent signal transduction in the inner ear. PACAP and its specific receptor also occur in the stria vascularis suggesting a role in endolymph production; furthermore, they are present in central pathways of the auditory system such as the cochlear nuclei, superior olivary complex, inferior colliculus, and medial geniculate body. PAC1-receptor is also present in the inner ear in PACAP-deficient mice, occurring at the same localization but with altered expression compared to wildtype mice. PACAP protects hair cells from $\mathrm{H}_{2} \mathrm{O}_{2}$-induced apoptosis in chicken inner ear cell cultures in vitro, and the lack of PACAP affects the $\mathrm{Ca}^{2+}$-binding protein expression in hair cells in PACAP-deficient mice under control circumstances and after ototoxic drug treatment.
\end{abstract}

Keywords $\mathrm{PACAP} \bullet \mathrm{PAC} 1-\mathrm{R} \bullet$ Inner ear $\bullet$ Auditory system $\bullet$ Ototoxicity

\footnotetext{
B.D. Fulop $\bullet$ D. Reglodi $\bullet$ A. Tamas $(\bowtie)$

Department of Anatomy, MTA-PTE “Lendulet” PACAP Research Team, Medical School, University of Pecs, Szigeti u. 12, Pecs 7624, Hungary

e-mail: andreatamassz@gmail.com
}
A. Nemeth
Department of Anatomy, MTA-PTE "Lendulet” PACAP Research Team, Medical School, University of Pecs, Szigeti u. 12, Pecs 7624, Hungary
Department of Oto-rhino-laryngology, University of Pecs, Pecs, Hungary

D. Reglodi, A. Tamas (eds.), Pituitary Adenylate Cyclase Activating

Polypeptide - PACAP, Current Topics in Neurotoxicity 11,

DOI 10.1007/978-3-319-35135-3_31 


\section{Abbreviations}

AC

Adenylate cyclase

ApoD

Apolipoprotein D

ApoJ

Apolipoprotein J

$\mathrm{Bad}$

Bax

bcl-2-associated death promoter

$\mathrm{Bcl}$ bcl-2-like protein 4

ChAT

B-cell lymphoma

CREB

Choline acetyltransferase

DBH

cAMP response element-binding protein

$\mathrm{HZ}$

Dopamine $\beta$-hydroxylase

ERK

Heterozygous PACAP-deficient mice

GluR2/3

Extracellular-signal-regulated kinase

JC-1

Glutamate receptor $2 / 3$

JNK

5,5',6,6'-Tetrachloro-1,1',3,3'-tetraethylbenzimi-dazolylcarbocyanine iodide

LW c-Jun N-terminal kinase

MNTB

Lateral wall

MTT assay

Medial nucleus of trapezoid body

nNOS

Colorimetric assay for assessing cell metabolic activity

$\mathrm{OC}$

Neuronal nitric oxide synthase

p38MAPK

Organ of Corti

P5

p38 mitogen-activated protein kinases

P7

5th postnatal day

7th postnatal day

PACAP Pituitary adenylate cyclase-activating polypeptide

PACAP KO Homozygous PACAP-deficient mice

PACAP38 1-38 Amino-acid isoform of PACAP

PAC1-R PAC1-receptor

PKA Protein kinase A

PLC Phospholipase C

ROS Reactive oxygen species

RT-PCR Reverse transcription-polymerase chain reaction

SG Spiral ganglion

SOC Superior olivary complex

VIP Vasoactive intestinal polypeptide

WT Wild type mice

\section{Introduction}

Pituitary adenylate cyclase-activating polypeptide (PACAP) is known as a general cytoprotective factor. It protects neuronal and non-neuronal cells against various injuries and also exerts protective effects in sensory organs (Chaps. 29 and 30). In 
this review we summarize the experiments on the effects of PACAP in the auditory system. We describe the occurrence of PACAP, and its specific receptor, PAC1receptor (PAC1-R), in the cochlea [1-3] and in the central pathways of the auditory system [4-6]. We also present the changes in PAC1-receptor expression in the inner ear of PACAP-deficient mice [7]. Thereafter, we discuss the functional changes in the inner ear related to PACAP. We summarize the effects of PACAP on the endolymph composition [8], on apoptosis in chicken inner ear cell cultures in vitro [9], and its effects on $\mathrm{Ca}^{2+}$-binding protein expression in hair cells [7, 10].

\section{PACAP and PAC1-R in the Cochlea}

Kawano et al. [3] studied the expression of PACAP mRNA in the cochlea of Wistar rats using RT-PCR and in situ hybridization techniques. The RT-PCR primers designed against PACAP mRNA yielded the expected 553 bp RNA sequence. In situ hybridization returned cytoplasmic labeling, in most cells of the spiral ganglion and in the marginal cells of stria vascularis in the lateral wall.

Abu-Hamdan et al. [1] investigated the expression of PACAP and different splice variants of PAC1-R in rat cochlea. They divided the cochlea into three subfractions, such as organ of Corti (OC), spiral ganglion (SG), and lateral wall (LW) (Fig. 31.1).

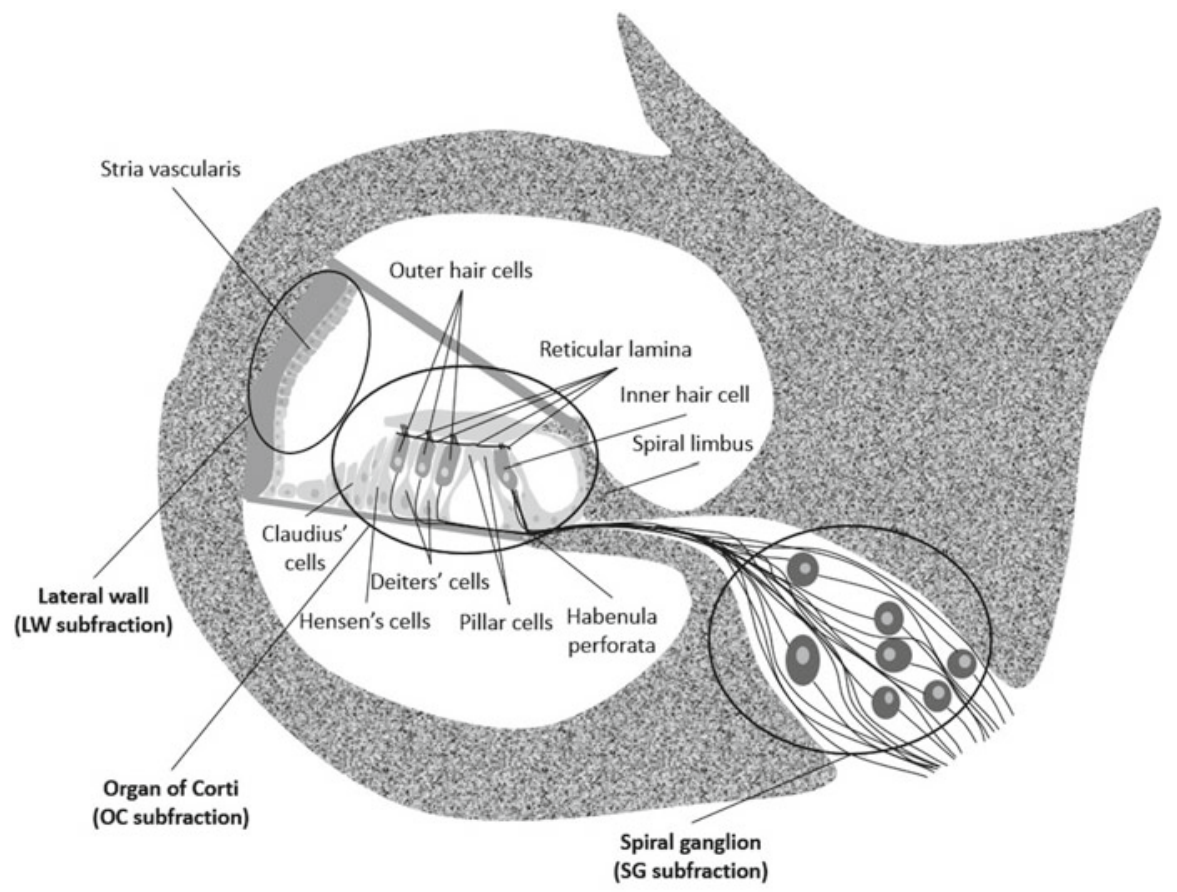

Fig. 31.1 Schematic drawing of the cochlea showing lateral wall (LW), organ of Corti (OC), and spiral ganglion (SG) subfractions 
They were working with ACI Black Agouti (Harlan Sprague-Dawley) rats of both sexes. First they examined the expression of PACAP in the cochlea of 20-day-old rats using RT-PCR. Amplification products of predicted size were present in all three cochlear subfractions. For PAC1-R all the three subfractions contained mRNA for the short splice variant $(\sim 842 \mathrm{bp})$ of the third intracellular loop. Additional amplification products were found in the LW fraction, which represents other splice variants such as formerly known hop1, hop2, hip, and a new hop1 variant with a 193 bp deletion in the carboxyl-terminal corresponding region. Western blot technique confirmed the presence of PAC1-R short splice variant in 6-week-old rats with a $\sim 53 \mathrm{kDa}$ band in all three subfractions and a $\sim 49 \mathrm{kDa}$ in the LW fraction, which might represent the novel hop1 variant. Hip-hop1 or hip-hop2 variants were not present in the cochlear subfractions based on sequencing results. The primers designed against the amino terminus corresponding region showed the presence of one amplification product at $\sim 500 \mathrm{bp}$ in all three subfractions in accordance with previously described sequences [11]. This was also confirmed by Western blot, showing a band at $\sim 70 \mathrm{kDa}$ in all three subfractions. Additionally they found a new variant in the OC subfraction with a 7-amino acid deletion. There were no amplification products indicating the presence of other, previously described splice variants [12, 13]. Further Western blot examinations suggested that PAC1-R splice variants are glycosylated in LW and OC subfractions.

They also used immunohistology in the LW subfraction in 2-month-old rats where PACAP and PAC1-R were found mainly in the stria vascularis. The immunoreactivity increased from basal to apical turns. Immunoreactivity is shown in the basolateral extension of marginal cells as predicted from earlier in situ hybridization of the mRNA of PACAP preprotein by Kawano et al. [3]. No PACAP immunoreactivity was detected in the apical membrane of the marginal cells, basal cells, capillaries, nor in fibroblasts of the spiral ligament. PAC1-R was associated with the basolateral extension of the marginal cells in the stria vascularis. PAC1-R immunoreactivity was also present in the capillary endothelium, and between the marginal cells close to the apical surface in the region of tight junctions. However, there was no PAC1-R immunoreactivity either in the basal cells or in the apical membrane of the marginal cells. The co-expression of PACAP and its receptor on the marginal cells suggests an autocrine/intracrine mechanism of PACAP which was described earlier in several other cell types [14]. PACAP either might be secreted from the marginal cells or could enter from blood plasma. The activation of PAC1-R in the lateral membranes of marginal cells may lead to the activation of protein kinase $A$ (PKA), which mediates the phosphorylation of claudin-3, which is a protein responsible for tight-junction integrity [15-17]. This can affect tight junction functions, which play a role in cell permeability, polarity, and possibly also establishing the endolymphatic potential. The proximity of $\mathrm{K}^{+}$channels to PAC1-R suggests the role of PACAP in the regulation of the $\mathrm{K}^{+}$transport by affecting the IsK $\mathrm{K}^{+}$-channels at the apical and $\mathrm{Na}^{+}-\mathrm{K}^{+}-\mathrm{Cl}^{-}$-cotransporter and/or $\mathrm{Na}^{+}-\mathrm{K}^{+}$-ATPase at the basolateral extensions of the marginal cells through the cAMP-PKA signaling pathway [15].

Drescher et al. [2] examined the localization of PACAP, PAC1-R, and several afferent and efferent neuronal markers [choline acetyltransferase (ChAT), gluta- 
PACAP - apical turn

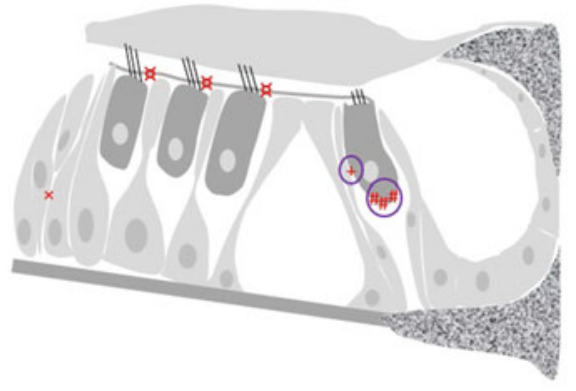

PAC1-R - apical turn

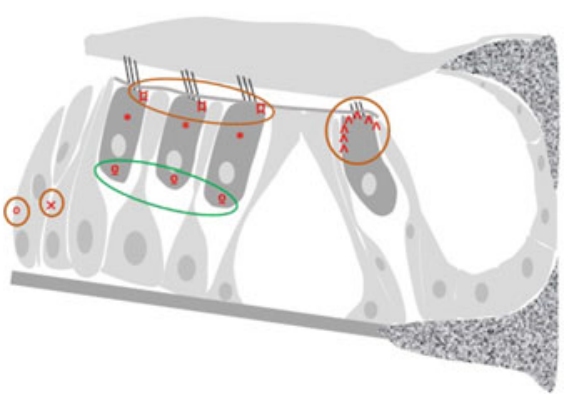

Fig. 31.2 Localization of PACAP and PAC1-R in the organ of Corti in the apical turn of the cochlea. PACAP immunoreactivity: cup under the inner hair cell (\#), between inner hair cell and inner pillar cell $(+)$, reticular lamina at the outer hair cell region $(\propto)$, Hensen's cell region $(x)$. PAC1-R immunoreactivity: sites at the apical part of the outer hair cells $(*)$, inverted $\mathrm{V}$ form at the apical site of the inner hair cell $(\wedge)$, base of the outer hair cells ( $\underline{\mathrm{o}})$, reticular lamina in the outer and inner hair cell regions ( $\mathrm{x}$ ), Hensen's cell region (x), Claudius' cell region (o). green circle: colocalization with GluR2/3; purple circle: colocalization with ChAT; brown circle: colocalization with DBH
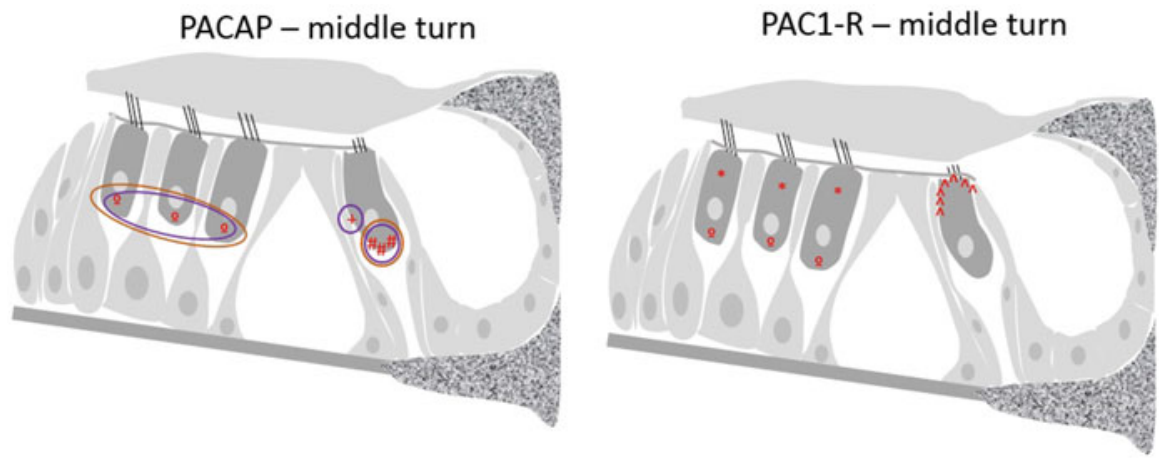

Fig. 31.3 Localization of PACAP and PAC1-R in the organ of Corti in the middle turn of the cochlea. PACAP immunoreactivity: cup under the inner hair cell (\#), between inner hair cell and inner pillar cell (+), base of the outer hair cells (o). PAC1-R immunoreactivity: sites at the apical part of the outer hair cells $(*)$, base of the outer hair cells (o), inverted $\mathrm{V}$ form at the apical site of the inner hair cell $\left({ }^{\wedge}\right)$. purple circle: colocalization with ChAT; brown circle: colocalization with $\mathrm{DBH}$

mate receptor $2 / 3$ (GluR2/3), dopamine $\beta$-hydroxylase (DBH)] with immunohistochemistry in the cochlea of 2-month-old ACI Black Agouti rats. Their aim was to show the localization of PACAP and PAC1-R in the organ of Corti (Figs. 31.2, 31.3, and 31.4) and spiral ganglion, and elucidate the role of PACAP in the afferent and efferent signaling of the inner ear.

PACAP was found at the base of outer hair cells in the basal and middle turns, in small-caliber nerve fibers under and lateral of inner hair cells forming an efferent 

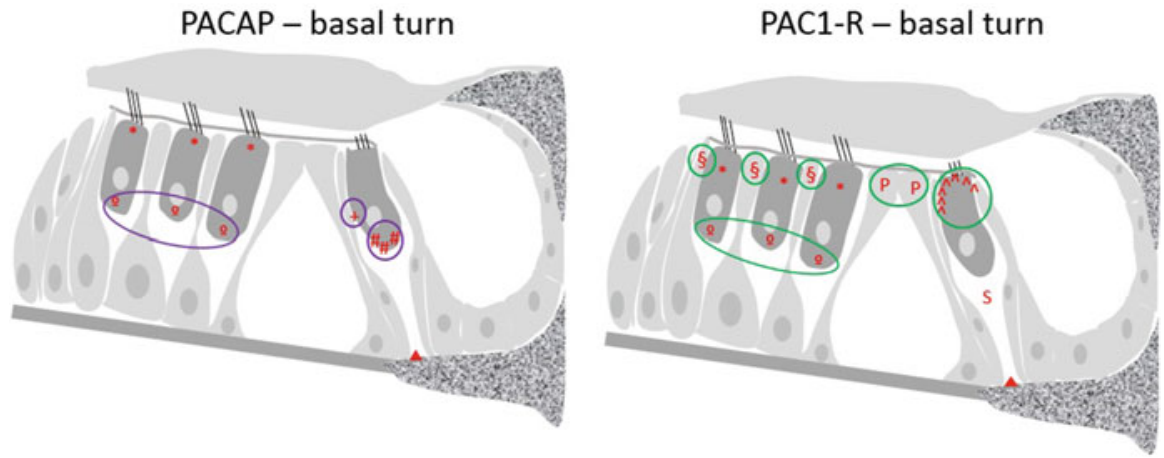

Fig. 31.4 Localization of PACAP and PAC1-R in the organ of Corti in the basal turn of the cochlea. PACAP immunoreactivity: cup under the inner hair cell (\#), lateral from inner hair cell $(+)$, base of the outer hair cells $(\underline{o})$, apical part of the outer hair cells $(*)$, habenula perforata (filled triangle). PAC1-R immunoreactivity: sites at the apical part of the outer hair cells $(*)$, inverted V form at the apical site of the inner hair cell $(\wedge)$, habenula perforata (filled triangle), base of the outer hair cells (o), apical site of Deiters' cells (§), head of the inner and outer pillar cells (P), diagonal fibers under the inner hair cell (S). green circle: colocalization with GluR2/3; purple circle: colocalization with ChAT

cup in all three turns. ChAT showed colocalization with PACAP in these regions and in the middle turn they also showed colocalization with DBH. PACAP immunoreactivity was found in small-caliber nerve fibers approaching and crossing the habenula perforata, and at the apical sites of the outer hair cells in the basal turns. The fibers at the apical sites of the outer hair cells may represent PACAP containing efferent fibers. PACAP was also present in the reticular lamina at the outer hair cell region and in the Hensen's cell region in the apical turn (Figs. 31.2, 31.3, and 31.4). Colocalization of PACAP and ChAT was also shown in the intraganglionic efferent fibers of the spiral ganglion. PACAP also showed colocalization with DBH, in similar regions, reflecting probably adrenergic neurons. Strong PACAP immunostaining was found in the cochlear nerve in the axons of afferents leaving the spiral ganglion (Fig. 31.1), corresponding to previous PACAP preprotein mRNA findings of Kawano et al. [3]. Although type I axons had high immunoreactivity the cell bodies showed low density of immunoreactivity which suggests afferent axonal transport of PACAP in these cells, presumably to modulate excitatory amino acid release at the axon terminals of the afferent cells in the cochlear nucleus. The efferent intraganglionic spiral bundle showed also PACAP immunoreactivity. These smallcaliber nerve fibers were overlapping type I/II afferent cell bodies and showing colocalization with ChAT.

PAC1-R immunoreactivity was found in small-caliber nerve fibers approaching the habenula perforata in the basal turn. It was also found as an inverted $\mathrm{V}$ form at the apical site of the inner hair cells in all three turns, showing colocalization with GluR2/3 in the basal and with DBH in the apical turns. PAC1-R was also found at the base and at the apical part of the outer hair cells in all three turns, at the base colocalizing with Glu2/3 in the basal and apical turns. It was also found in nerve 
fibers at the head of the inner and outer pillar cells in the basal turn also colocalizing with GluR2/3. It was also found in the reticular lamina in the outer hair cell regions in the apical turn, showing colocalization with $\mathrm{DBH}$, and in diagonal fibers under the inner hair cell in the basal turn. Regarding the supporting cells there was PAC-1R immunopositivity at the apical site of Deiters' cells in the basal turn (GluR2/3 colocalization), and in the Hensen's and Claudius' cell region in the apical turns colocalizing with DBH (Figs. 31.2, 31.3 and 31.4). PAC1-R immunoreactivity was found in type I afferent cells in the spiral ganglion, in small-caliber nerve fibers in the spiral limbus, and in the cochlear nerve.

PACAP showed colocalization with ChAT and DBH in the efferent cholinergic and adrenergic fibers suggesting that PACAP acts as an efferent neuromodulator in the inner ear. It is known that type I afferents of the inner hair cells get cholinergic and partially dopaminergic afferentation from lateral olivocochlear fibers [18, 19]. Dopamine acts as a protective neurotransmitter in case of excitotoxicity for type I afferents [20,21] and PACAP is able to upregulate dopaminergic functions [22]. Drescher et al. [2] showed more evidence for the previous findings of Spoendlin [23], that adrenergic efferent innervation is also present in different sites of the organ of Corti, such as supranuclear sites of inner and outer hair cells, and Deiters' and Hensen's cell regions. PACAP is associated with adrenergic nerve terminals [24] and takes part in the modification of adrenergic functions [25].

Glutamate is the primary neurotransmitter in the cochlea $[18,26]$ and the release of glutamate in acoustic trauma/ischemia may lead to cell death and destruction of the afferent nerve endings [27, 28]. Morio et al. [29] showed that in neuronal cells PACAP suppressed glutamate-induced cell death. Drescher et al. [2] demonstrated the presence of PAC1-R in cell bodies and dendrites of type I afferent cells in the spiral ganglion. It also showed colocalization with GluR2/3 under the outer hair cells in the organ of Corti suggesting that PACAP interacts directly with glutamatemediated signal transduction in the auditory system. Based on these finding PACAP may prevent glutamate-induced cell death in the inner ear upon various insults.

Our research group examined the inner ear of wild type (WT), heterozygous (HZ) and homozygous PACAP-deficient (KO) mice [7]. The gross anatomical morphology of PACAP-deficient mice is similar to the WT mice, but they maintain an increased vulnerability against various insults and have an altered behavior, decreased reproductive function and several biochemical alterations [30]. Partial lack of PACAP also leads to higher vulnerability of heterozygous PACAP-deficient mice [31-35]. We used hematoxylin-eosin staining to show the microscopic structure of the inner ear, and immunofluorescent staining against PAC1-R. The morphology of the inner ear showed no differences between the homozygous PACAP-deficient and WT mice. Our research group found PAC1-R immunopositivity in both inner and outer hair cells, outer phalangeal cells (Deiters' cells), and pillar cells in accordance with the previous results of Kawano et al. [3], AbuHamdan et al. [1] and Drescher et al. [2]. The localization of PAC1-R immunoreactivity did not show any differences between homozygous PACAP-deficient and WT mice, but in PACAP-deficient mice the hair cells and outer phalangeal cells showed lower intensity of PAC1-R immunoreactivity compared to WT mice. 


\section{PACAP in the Brainstem and Thalamus}

Hannibal [4] used mouse monoclonal antibody to show PACAP immunoreactivity in the adult rat brain (Fig. 31.5). The cell bodies and nerve fibers of the cochlear nuclei (especially the ventral cochlear nuclei) showed moderate PACAP expression. Furthermore the root of the cochlear nerve showed also PACAP immunoreactivity. The deep layer of inferior colliculus contained also weak PACAP positive cell bodies and nerve fibers. Nerve fibers showed weak PACAP immunoreactivity in the medial geniculate body (Fig. 31.5). Palkovits et al. [36] also found PACAP in the inferior colliculus and medial geniculate nucleus in human brain samples with radioimmunoassay examination.

Kausz et al. [5] found PACAP immunoreactive cell bodies in the dorsal and ventral cochlear nucleus, superior olivary complex (SOC), and trapezoid nucleus (Fig. 31.5). Reuss et al. [6] described the localization of PACAP, vasoactive intestinal polypeptide

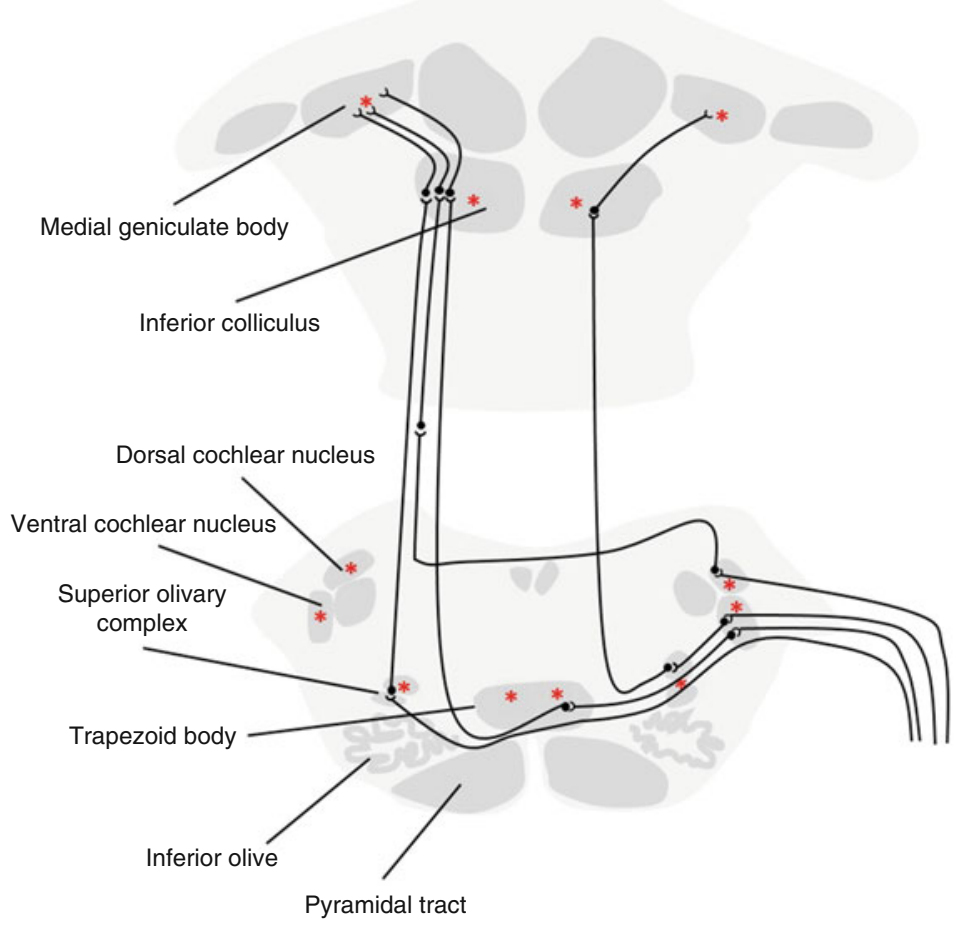

Fig. 31.5 Schematic picture of the auditory pathway showing the occurrence of PACAP in the brainstem and thalamus. PACAP immunoreactivity was present in cell bodies and nerve fibers of dorsal and ventral cochlear nuclei. It was also found in several parts of the superior olivary complex (SOC), such as the medial nucleus of the trapezoid body (MNTB), medial superior olive, ventral nucleus of the trapezoid body. PACAP immunopositive cell bodies were also found in the inferior colliculus, and PACAP immunoreactive nerve fibers in the medial geniculate body 
(VIP), neuronal nitric oxide synthase (nNOS) and other neurotransmitters in the SOC in adult male Djungarian hamsters (phodopus sungorus) using immunohistochemistry and retrograde tracing. PACAP immunoreactivity was found in approximately one third of all neurons, whereas VIP was not present in the neurons of the SOC. PACAP was present in many large neurons of the medial nucleus of the trapezoid body (MNTB) and in the medial superior olive. These cells are suggested to project to the lateral superior olive, periolivary regions, and inferior colliculus [37]. The large PACAP-immunopositive neurons of the medial superior olive were also nNOS positive. One fourth of all neurons contained PACAP in the lateral superior olive and in the periolivary regions. $40 \%$ of the olivocochlear neurons, which were positive with fluorochrome after the retrograde tracing in MNTB and ventral nucleus of the trapezoid body, were also positive for PACAP, such as some periolivary neurons (Fig. 31.5). Therefore, these cells could serve as the origin of PACAP found in the cochlea by Kawano et al. [3]. PACAP was found in the medial olivocochlear efferents, which target the outer hair cells, but not in the lateral olivocochlear efferents, which target the inner hair cells. This further substantiates the theory of Drescher et al. [2] that PACAP plays a greater role in the efferent signaling of the cochlea, and through it an indirect effect on the afferent signaling.

\section{Functional Studies}

\section{Effects of PACAP on the Endolymph Composition}

Our research group examined the protein composition of chicken endolymph after PACAP38 treatment [8]. We treated 1-day-old chicken with intraperitoneal PACAP38 injection. Endolymph was collected 1, 6, and $24 \mathrm{~h}$ after PACAP38 injection. Then we removed the membranous labyrinth and the endolymph was squeezed to a sterile paper strip. Then we utilized microchip electrophoresis using protein 230 Plus LabChip Kit evaluated with Agilent 2100 Bioanalyzer System [8].

Endolymph, which fills the membranous labyrinth, is produced in the stria vascularis, it is rich in potassium and poor in sodium. However, perilymph, which fills the scala tympani and vestibuli, is rich in sodium and poor in potassium. Although endolymph is derived from the plasma, its composition resembles more the composition of the intracellular fluid. Endolymph affects several physiological and pathological functions of the labyrinth [38,39]. Several neuropeptides have an influence on endolymph secretion, e.g., substance $P$, vasopressin, and somatostatin [40, 41]. Abu-Hamdan et al. [1] described the presence of PACAP and PAC1-R in the stria vascularis. The expression of the peptide and its receptor increases from basal to apical turns. Basal-apical gradient of other components, such as the endolymphatic potential [42] and endolymphatic $\mathrm{K}^{+}$and $\mathrm{Cl}^{-}$concentrations [43] in the cochlea had already been described. The gradient present in both PACAP and PAC1-R might be partly the cause for these gradients, as they could contribute to the maintenance of endolymphatic potential through regulating the tight junction permeability in the stria vascularis. Based on these results we aimed at elucidating the role of PACAP in endolymph production. 
However, there are no data for the protein composition of chicken endolymph, it is well described in other species. It has been studied mostly in human and guinea pigs samples. It yields a complex protein composition containing albumin, $\alpha$-chymotrypsin, $\alpha$-antitrypsin, transferrin, apolipoprotein D (ApoD), apolipoprotein $\mathbf{J}$ (ApoJ), fetuin, and other proteins. The composition of these proteins is similar to the perilymph, but the level of proteins is approximately the $15-20 \%$ of the perilymph levels. That could be based on the mechanism of production, such as the proteins of the endolymph are filtered from the perilymph through the basal and marginal cells of the spiral ligament. Endolymph is rich in ApoD and ApoJ proteins which are at higher levels in the perilymph and liquor but low in the blood plasma. Their function is presumably to protect the integrity of the extracellular membranes bordering the endolymphatic space.

In our experiment we found several protein peaks between 14 and $80 \mathrm{kDa}$, the range where the majority of the above mentioned proteins are located. There was no significant difference between control and PACAP-treated groups at any given time. Based on these results we can conclude that under the given circumstances there was no change on the composition of the endolymph proteins after PACAP treatment. However, these negative findings can be a consequence of the chosen circumstances. We could not exclude that other species, route of PACAP administration or applied dose would cause significant changes in the protein composition of the endolymph.

\section{Effects of PACAP on Apoptosis in an Inner Ear Cell Culture In Vitro}

Although physiological apoptosis is essential in the development of the inner ear, increased apoptosis, caused by toxins, acoustic overstimulation, oxidative stress, infections, etc., leads to permanent cell damage and loss of hearing [44, 45]. Oxidative stress is highly involved in these pathological conditions, hence antioxidative and antiapoptotic drugs, among others PACAP [46-48], could be used as inner ear protecting factors $[49,50]$. Our research group studied the effects of PACAP on apoptosis in a chicken in vitro cell culture model [9] which contained both sensory hair cells and supporting cells. We used 6 series of 40 newly hatched chickens for this study. Chicken cochlea is simpler and easier to dissect, therefore, a favorite model for cochlear experiments, since the reactive oxygen species (ROS) generation and apoptotic reaction to toxic agents (e.g., aminoglycoside) is similar to mammals [51-53]. We used $\mathrm{H}_{2} \mathrm{O}_{2}$ as a ROS generating molecule for causing cell death via oxidative stress. Treatment lasted 2 hours, and evaluation followed immediately thereafter.

MTT assay showed that there were more than $90 \%$ living cells in the control group and PACAP treatment alone did not result in significant alterations. It also showed that $\mathrm{H}_{2} \mathrm{O}_{2}$ treatment led to a significant drop in cell viability and an increase in the number of apoptotic and necrotic cells. Cell viability significantly increased when $\mathrm{H} \mathrm{O}$-treated cells were co-incubated with PACAP. JC-1 assay is for the detection of apoptosis, and this staining also showed higher cell viability in case of $\mathrm{H}_{2} \mathrm{O}_{2}$ 
and PACAP co-administration compared to $\mathrm{H}_{2} \mathrm{O}_{2}$ treatment. AnnexinV and propidium iodide co-staining verified these results: co-administration of PACAP with $\mathrm{H}_{2} \mathrm{O}_{2}$ resulted in a significant increase of living cells, and significant decrease of apoptotic cells compared to the $\mathrm{H}_{2} \mathrm{O}_{2}$-treated group. There was also a decrease in the number of necrotic cells compared to the $\mathrm{H}_{2} \mathrm{O}_{2}$-treated group, but the difference was not significant. The protected cells are suggested to be primarily sensory hair cells, as the used $\mathrm{H}_{2} \mathrm{O}_{2}$ concentration causes damage to the hair cells with no injury to other neuroepithelial cells [54].

These antiapoptotic effects of PACAP were verified by the regression of the activation of the caspase- 3 apoptotic protein in case of PACAP and $\mathrm{H}_{2} \mathrm{O}_{2}$ co-treatment compared to the $\mathrm{H}_{2} \mathrm{O}_{2}$-treated cells. The protective effect of PACAP is based on several molecular signaling pathways. Most of these effects is mediated by PAC1-R $[55,56]$. PAC1-R activates adenylate cyclase (AC) and phospholipase C (PLC). AC activation leads to the activation of the PKA signaling pathways resulting in the elevation of the antiapoptotic extracellular-signal-regulated kinase (ERK), phosphorylation of cAMP response element-binding protein (CREB), and inhibition of proapoptotic c-Jun N-terminal kinase (JNK) and p38 mitogen-activated protein kinases (p38MAPK). PACAP also affects the intrinsic mitochondrial pathway of apoptosis, through activation of the antiapoptotic members of the Bcl peptide family (Bcl-2, Bcl-xL) and inhibition of the proapoptotic Bad, Bax. These effects are moderated partly through the 14-3-3 protein, which phosphorylates Bad, therefore, it is not able to bind and inactivate Bcl-2 and Bcl-xL. These effects result in decreased release of cytochrome $c$ from the mitochondria, which also results in the inhibition of apoptosis. PLC activation leads to decreased caspase activation through inositol trisphosphate and diacylglycerol pathways. The antiapoptotic effects and the inhibition of caspase- 3 activation could provide the molecular background, how PACAP can protect the inner ear cells against glutamatergic excitotoxicity, aminoglycoside, or other drug effects, during acoustic overstimulation or in other pathological conditions.

\section{Effects of PACAP on Ca ${ }^{2+}$-Binding Protein Expression of Hair Cells}

We investigated the effects of endogenous PACAP on hair cell $\mathrm{Ca}^{2+}$-binding protein composition under control circumstances and in kanamycin induced ototoxicity [7, 10]. The $\mathrm{Ca}^{2+}$-concentration in the endolymph and the intracellular $\mathrm{Ca}^{2+}$ concentration in the hair cells are strictly regulated and important for normal hearing processes [57]. Several pathological conditions lead to elevated $\mathrm{Ca}^{2+}$ concentration in endolymph and hair cells, such as acoustic overstimulation [58, 59], drug induced ototoxicity [60], vestibular labyrinth destruction [57], and surgically induced endolymphatic hydrops [61]. The subsequent high intracellular $\mathrm{Ca}^{2+}$ concentration is toxic to cells $[62,63]$. $\mathrm{Ca}^{2+}$-buffering proteins (calretinin, parvalbumin, calbindin, etc.) presumably play an essential role in regulating the $\mathrm{Ca}^{2+}$ level of hair cells and may protect them against the toxic effects of high intracellular $\mathrm{Ca}^{2+}$ concentration [64-68]. 
We used 5-day-old (P5) and 7-day-old (P7) WT, HZ, and PACAP KO mice in the experiments. We chose this age group because the development of the inner ear of mice still goes on during this period of time and all three $\mathrm{Ca}^{2+}$-binding proteins are present in the inner and outer hair cells on these postnatal days based on previous studies in various animal species [65]. To model toxic insults to the inner ear we chose kanamycin as an ototoxic agent. It is a member of the aminoglycoside antibiotics, which are widely used in the clinical practice together with the platinum based chemotherapeutics although possibly causing permanent cochlear damage [69]. Kanamycin causes hair cell damage mainly through ROS production; hence antioxidant and antiapoptotic drugs (such as PACAP) can be possibly used as otoprotective agents $[69,70]$.

We used immunofluorescent staining against $\mathrm{Ca}^{2+}$-binding proteins on sections produced from the cochlea on P5 and P7. Mice sacrificed on P5 did not receive any treatment, mice sacrificed on P7 were treated with one dose of kanamycin $(1 \mathrm{mg} / \mathrm{g}$ body weight) or physiological saline as a control on P5. The localization of parvalbumin, calretinin, and calbindin was in accordance with previously described results and did not show any differences between the groups. However, we found significant alterations in the $\mathrm{Ca}^{2+}$-binding protein density. All three $\mathrm{Ca}^{2+}$-binding proteins showed stronger immunopositivity in the hair cells of homozygous PACAP-deficient mice, than in WT mice on P5. We found similar results for parvalbumin (Fig. 31.6a, e) and calretinin (Fig. 31.7:a, e) on P7 in the physiological saline treated groups (calbindin was not examined on P7). Parvalbumin and calretinin immunopositivity was especially pronounced in the hair bundles of the hair cells. Heterozygous PACAPdeficient animals in the physiological saline group also showed higher expression of calretinin (Fig. 31.7a, c) in inner and outer hair cells, and higher expression of parvalbumin in the outer hair cells compared to WT mice (Fig. 31.6a, c) on P7.

Parvalbumin expression in the hair cells of both WT and heterozygous PACAPdeficient mice was elevated after kanamycin treatment on P7, and the expression was significantly higher in the heterozygous PACAP-deficient mice, compared to WT mice (Fig. 31.6a-d). The baseline stronger parvalbumin immunopositivity of homozygous PACAP-deficient mice did not increase further upon kanamycin treatment (Fig. 31.6e, f). Calretinin immunolabeling yielded similar results in WT and homozygous PACAP-deficient mice (Fig. 31.7a, b, e, f) on P7 as parvalbumin. Heterozygous PACAP-deficient mice, similarly to homozygous PACAP-deficient mice showed high immunoreactivity of calretinin under control circumstances; therefore, after kanamycin treatment this higher baseline immunofluorescence did not increase further (Fig. 31.7c, d).

Apoptosis is caused by ROS generation in aminoglycoside induced ototoxicity, and leads to cell death through an extrinsic, death-receptor-mediated pathway and an intrinsic, mitochondria-mediated pathway [69, 71]. In case of aminoglycosideinduced ototoxicity the intrinsic pathway has a greater role by activating $\mathrm{G}$ proteins followed by stress-activated protein kinase activation (JNK). Subsequently cytochrome $c$ release, caspase- 8 and 9 activation and elevation of intracellular $\mathrm{Ca}^{2+}$ concentration follows $[62,63]$. The elevation of $\mathrm{Ca}^{2+}$ concentration and the activation of proapoptotic pathways can be prevented by increased expression of $\mathrm{Ca}^{2+}$ - 


\section{Parvalbumin - WT, control}

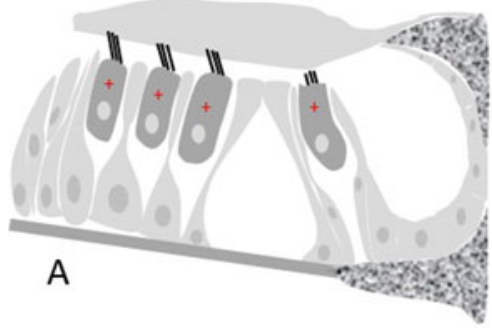

Parvalbumin $-\mathrm{HZ}$, control

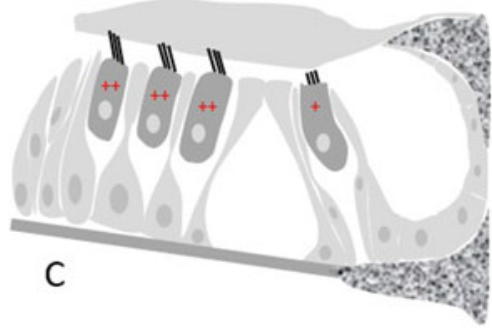

Parvalbumin - KO, control

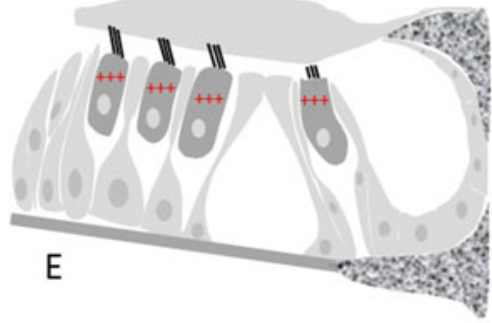

Parvalbumin - WT, kanamycin

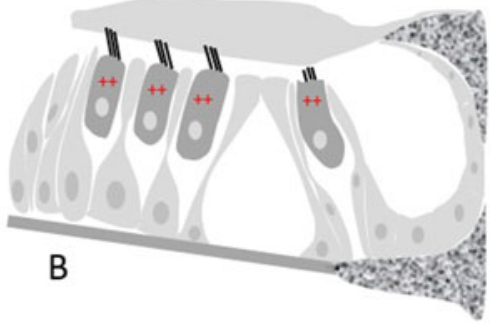

Parvalbumin - HZ, kanamycin

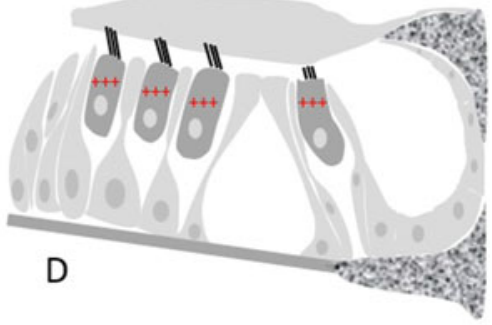

Parvalbumin - KO, kanamycin

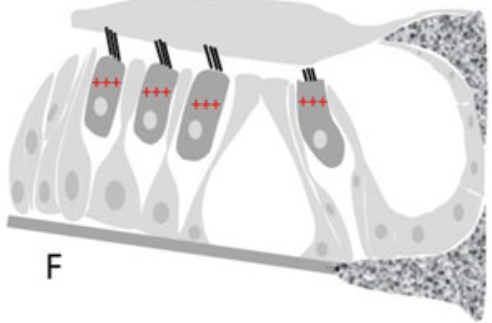

Fig. 31.6 Parvalbumin expression in inner and outer hair cells in wild-type (WT), heterozygous (HZ), and homozygous PACAP-deficient (KO) mice under control circumstances and after kanamycin treatment. + mild, ++ moderate, +++ strong immunoreactivity

binding proteins. When the buffer capacity of the $\mathrm{Ca}^{2+}$-binding proteins reaches its maximum the intracellular $\mathrm{Ca}^{2+}$ concentration increases and leads to the activation of apoptotic pathways [72].

Although the direct effect of PACAP is to elevate the intracellular $\mathrm{Ca}^{2+}$ concentration through PLC signaling [73] it was also shown in hippocampal neurons that PACAP can protect the cells against the glutamate-induced toxic $\mathrm{Ca}^{2+}$ concentration elevation [74]. Our results show that in the lack of PACAP the $\mathrm{Ca}^{2+}$-binding protein expression increases in the inner and outer hair cells, which is a probable endogenous compensatory mechanism against the elevated $\mathrm{Ca}^{2+}$ level in the hair cells caused by the lack of PACAP. However, the elevated $\mathrm{Ca}^{2+}$-binding protein level cannot be further upregulated upon ototoxic insults, as the $\mathrm{Ca}^{2+}$-binding protein expression reaches its maximum level. 


\section{Calretinin - WT, control}

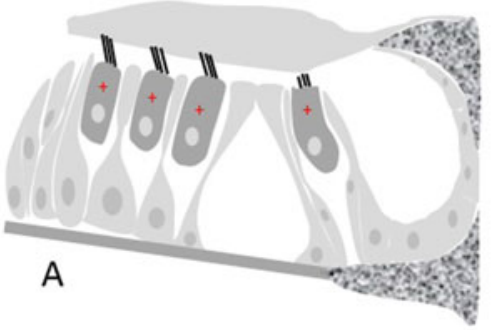

Calretinin $-\mathrm{HZ}$, control

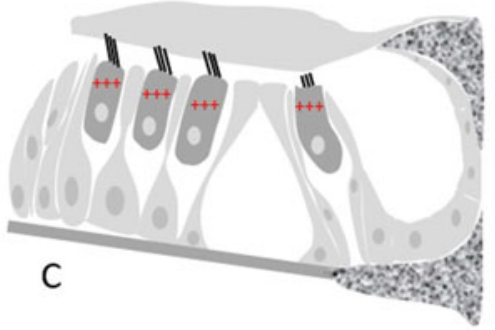

Calretinin - KO, control

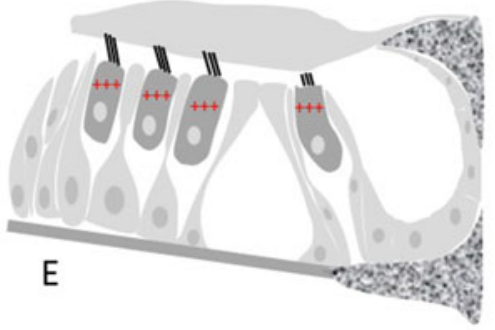

Calretinin - WT, kanamycin

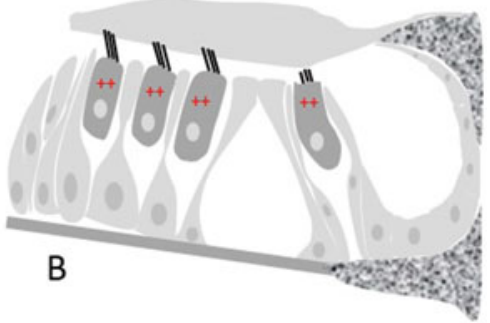

Calretinin - HZ, kanamycin

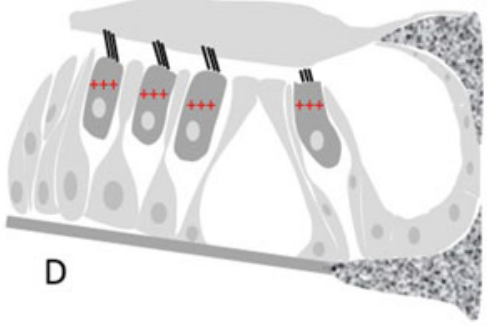

Calretinin - KO, kanamycin

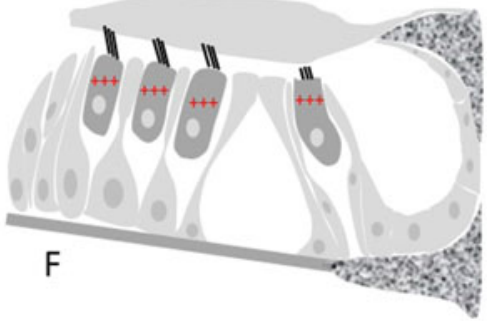

Fig. 31.7 Calretinin expression in inner and outer hair cells in wild-type (WT), heterozygous (HZ), and homozygous PACAP-deficient (KO) mice under control circumstances and after kanamycin treatment. + mild, ++ moderate, +++ strong immunoreactivity

\section{Discussion}

PACAP and PAC1-R were described in several parts of the auditory system. They are present in the organ of Corti in hair cells, supporting cells, and different nerve fibers. They were also showed in spiral ganglion and stria vascularis. Their presence in the stria vascularis suggests a role of PACAP affecting endolymph production which we tried to prove by studying the endolymph protein composition in chicken cochlea after PACAP treatment but we did not find any differences in this experimental setup. Colocalization of PACAP and PAC1-R with GluR2/3 and DBH in several structures in the cochlea, mostly efferent nerve fibers, suggests that PACAP 
could theoretically modulate glutamatergic, dopaminergic, cholinergic, and adrenergic efferents of hair cells, whereby they would also take place in the regulation of the afferent signaling. The presence of PACAP and its receptor PAC1-R was shown in several parts of the auditory pathway (cochlear nuclei, SOC, inferior colliculus, medial geniculate body). PACAP was found in the olivocochlear neurons in the SOC, which could serve as the origin of PACAP found in the cochlea.

PACAP protects the hair cells from $\mathrm{H}_{2} \mathrm{O}_{2}$ toxicity in vitro, increasing the number of living cells mostly through decreasing apoptosis. In PACAP-deficient mice there is a higher concentration of $\mathrm{Ca}^{2+}$-binding proteins in the hair cells, which is probably a protective mechanism against the hypothesized higher intracellular $\mathrm{Ca}^{2+}$ concentration caused by the pathological conditions in the lack of PACAP. Kanamycin treatment causes also $\mathrm{Ca}^{2+}$-binding protein level elevation in WT and HZ PACAPdeficient mice, but there is no further elevation in homozygous PACAP-deficient mice, where the baseline $\mathrm{Ca}^{2+}$-binding protein level is already elevated.

In summary, PACAP and PAC1-R are present and cause functional changes in the cochlea. With further examination we hope to prove the protective effects of the exogenous PACAP in ototoxicity in vivo and examine its role throughout various clinical studies.

Acknowledgement MTA-PTE "Lendulet" Program, OTKA K104984, 119759, Arimura Foundation, TAMOP 4.2.4.A/2-11-1-2012-0001 "National Excellence Program," New National Excellence Program (UNKP), Janos Bolyai Research Scholarship of Hungarian Academy of Sciences. This work is dedicated to the 650th anniversary of the University of Pecs.

\section{References}

1. Abu-Hamdan MD, Drescher MJ, Ramakrishnan NA, Khan KM, Toma VS, Hatfield JS, et al. Pituitary adenylyl cyclase-activating polypeptide (PACAP) and its receptor (PAC1- R) in the cochlea: evidence for specific transcript expression of PAC1-R splice variants in rat microdissected cochlear subfractions. Neuroscience. 2006;140:147-61.

2. Drescher MJ, Drescher DG, Khan KM, Hatfield JS, Ramakrishnan NA, Abu-Hamdan MD, et al. Pituitary adenylyl cyclase-activating polypeptide (PACAP) and its receptor (PAC1- R) are positioned to modulate afferent signaling in the cochlea. Neuroscience. 2006;142:139-64.

3. Kawano H, Shimozono M, Tono T, Miyata A, Komune S. Expression of pituitary adenylate cyclase-activating polypeptide mRNA in the cochlea of rats. Mol Brain Res. 2001;94:200-3.

4. Hannibal J. Pituitary adenylate cyclase-activating peptide in the rat central nervous system: an immunohistochemical and in situ hybridization study. J Comp Neurol. 2002;453:389-417.

5. Kausz M, Murai Z, Arimura A, Koves K. Distribution of pituitary adenylate cyclase activating polypeptide (PACAP) immunoreactive elements in the brain stem of rats studied by immunohistochemistry. Neurobiology. 1999;7:19-31.

6. Reuss S, Disque-Kaiser U,Antoniou-LipfertP, Gholi MN, Riemann E, Riemann R. Neurochemistry of olivocochlear neurons in the hamster. Anat Rec (Hoboken). 2009;292:461-71.

7. Tamas A, Szabadfi K, Nemeth A, Fulop B, Kiss P, Atlasz T, et al. Comparative examination of inner ear in wild type and pituitary adenylate cyclase activating polypeptide (PACAP)-deficient mice. Neurotox Res. 2012;21:435-44.

8. Gaal V, Mark L, Kiss P, Kustos I, Tamas A, Kocsis B, et al. Investigation of the effects of PACAP on the composition of tear and endolymph proteins. J Mol Neurosci. 2008;36:321-9. 
9. Racz B, Horvath G, Reglodi D, Gasz B, Kiss P, Gallyas Jr F, et al. PACAP ameliorates oxidative stress in the chicken inner ear: an in vitro study. Regul Pept. 2010;160:91-8.

10. Nemeth A, Szabadfi K, Fulop B, Reglodi D, Kiss P, Farkas J, et al. Examination of calciumbinding protein expression in the inner ear of wild-type, heterozygous and homozygous pituitary adenylate cyclase-activating polypeptide (PACAP)-knockout mice in kanamycin-induced ototoxicity. Neurotox Res. 2014;25:57-67.

11. Spengler D, Waeber C, Pantaloni C, Holsboer F, Boekaert J, Seeburg PH, et al. Differential signal transduction by five splice variants of the PACAP receptor. Nature. 1993;365:170-5.

12. Chatterjee TK, Sharma RV, Fisher RA. Molecular cloning of a novel variant of the pituitary adenylate cyclase-activating polypeptide (PACAP) receptor that stimulates calcium influx by activation of L-type calcium channels. J Biol Chem. 1996;271:32226-32.

13. Dautzenberg FM, Mevenkamp G, Wille S, Hauger RL. N-terminal splice variants of the type I PACAP receptor: isolation, characterization and ligand binding/selectivity determinants. J Neuroendocrinol. 1999;11:941-9.

14. Shintani N, Suetake S, Hashimoto H, Koga K, Kasai A, Kawaguchi C, et al. Neuroprotective action of endogenous PACAP in cultured rat cortical neurons. Regul Pept. 2005;126:123-8.

15. Drescher MJ, Khan KM, Hatfield JS, Shakir AH, Drescher DG. Immunohistochemical localization of adenylyl cyclase isoforms in the lateral wall of the rat cochlea. Mol Brain Res. 2000;76:289-98.

16. Florian P, Amasheh S, Lessidrensky M, Todt I, Bloedow A, Ernst A, et al. Claudins in the tight junctions of stria vascularis marginal cells. Biochem Biophys Res Commun. 2003;304:5-10.

17. Kitajiri S, Furuse M, Morita K, Saishin-Kiuchi Y, Kido H, Ito J, et al. Expression patterns of claudins tight junction adhesion molecules in the inner ear. Hear Res. 2004;187:25-34.

18. Eybalin M. Neurotransmitters and neuromodulators of the mammalian cochlea. Physiol Rev. 1993;73:309-73.

19. Morley BJ, Li H-S, Hiel H, Drescher DG, Elgoyhen AB. Identification of the subunits of the nicotinic cholinergic receptors in the rat cochlea using RT-PCR and in situ hybridization. Mol Brain Res. 1998;53:78-87.

20. D'Aldin C, Puel JL, Leducq R, Crambes O, Eybalin M, Pujol R. Effects of a dopaminergic agonist in the guinea pig cochlea. Hear Res. 1995;90:202-11.

21. Pujol R, Puel JL. Excitotoxicity, synaptic repair, and functional recovery in the mammalian cochlea: a review of recent findings. Ann N Y Acad Sci. 1999;884:249-54.

22. Anderson ST, Kusters DHL, Clarke IJ, Pow DV, Curlewis JD. Expression of pituitary adenylate cyclase activating polypeptide type 1 receptor (PAC1R) in the ewe hypothalamus: distribution and colocalization with tyrosine hydroxylase-immunoreactive neurones. J Neuroendocrinol. 2005; 17:298-305.

23. Spoendlin H. Primary neurons and synapses. In: Friedmann I, Ballantyne J, editors. Ultrastructural atlas of the inner ear. London: Butterworths; 1984. p. 133-64.

24. Shioda S, Yada T, Muroya S, Uramura S, Nakajo S, Ohtaki H, et al. Functional significance of colocalization of PACAP and catecholamine in nerve terminals. Ann N Y Acad Sci. 2000;921:211-7.

25. May V, Beaudet MM, Parsons RL, Hardwick JC, Gauthier EA, Durda JP, et al. Mechanisms of pituitary adenylate cyclase activating polypeptide (PACAP)-induced depolarization of sympathetic superior cervical ganglion (SCG) neurons. Ann N Y Acad Sci. 1998;865:164-75.

26. Matsubara A, Laake JH, Davanger S, Usami S, Ottersen OP. Organization of AMPA receptor subunits at a glutamate synapse: a quantitative immunogold analysis of hair cell synapses in the rat organ of Corti. J Neurosci. 1996;16:4457-67.

27. Puel JL. Chemical synaptic transmission in the cochlea. Prog Neurobiol. 1995;47:449-76.

28. Pujol R, Puel JL, Gervais d'Aldin C, Eybalin M. Pathophysiology of the glutamatergic synapses in the cochlea. Acta Otolaryngol Stockh. 1993;113:330-4.

29. Morio H, Tatsuno I, Hirai A, Tamura Y, Saito Y. Pituitary adenylate cyclase-activating polypeptide protects rat-cultured cortical neurons from glutamate-induced cytotoxicity. Brain Res. 1996;741:82-8. 
30. Reglodi D, Kiss P, Szabadfi K, Atlasz T, Gabriel R, Horvath G, et al. PACAP is an endogenous protective factor-insights from PACAP-deficient mice. J Mol Neurosci. 2012;48:482-92.

31. Endo K, Nakamachi T, Seki T, Kagami N, Wada Y, Nakamura K, et al. Neuroprotective effect of PACAP against NMDA-induced retinal damage in the mouse. J Mol Neurosci. 2011;43:22-9.

32. May V, Vizzard MA. Bladder dysfunction and altered somatic sensitivity inPACAP-/- mice. J Urol. 2010;183:772-9.

33. Nakamachi T, Ohtaki H, Yofu S, Watanabe J, Mori H, Sato A, et al. Endogenous pituitary adenylate cyclase activating polypeptide is involved in suppression of edema in the ischemic brain. Acta Neurochir Suppl. 2010;106:43-6.

34. Ohtaki H, Nakamachi T, Dohi K, Aizawa Y, Takaki A, Hodoyama K, et al. Pituitary adenylate cyclase-activating polypeptide (PACAP) decreases ischemic neuronal cell death in association with IL-6. Proc Natl Acad Sci U S A. 2006;103:7488-93.

35. Tsuchikawa D, Nakamachi T, Tsuchida M, Wada Y, Hori M, Farkas J, et al. Neuroprotective effect of endogenous pituitary adenylate cyclase-activating polypeptide on spinal cord injury. J Mol Neurosci. 2012;48:508-17.

36. Palkovits M, Somogyvari-Vigh A, Arimura A. Concentrations of pituitary adenylate cyclase activating polypeptide (PACAP) in human brain nuclei. Brain Res. 1995;699:116-20.

37. Schwartz IR. The superior olivary complex and lateral lemniscal nuclei. In: Webster DB, Popper AN, Fay RF, editors. The mammalian auditory pathway: neuroanatomy. New York: Springer; 1992. p. 117-67.

38. Fukushima K, Takeda T, Kakigi A, Takeda S, Sawada S, Nishioka R, et al. Effects of lithium on endolymph homeostasis and experimentally induced endolymphatic hydrops. ORL J Otorhinolaryngol Relat Spec. 2005;67:282-8.

39. Hanner P, Jennische E, Lange S, Lonnroth I, Wahlstrom B. Increased antisecretory factor reduces vertigo in patients with Meniere's disease: a pilot study. Hear Res. 2004;190:31-6.

40. Ferrary E, Sterkers O. Mechanisms of endolymph secretion. Kidney Int Suppl. 1998;65:S98-103.

41. Kitano H, Suzuki M, Kitanishi T, Yazawa Y, Kitajima K, Isono T, et al. Regulation of inner ear fluid in the rat by vasopressin. Neuroreport. 1999;10:1205-7.

42. Misrahy GA, Hildreth KM, Shinabarger EW, Gannon WJ. Electrical properties of wall of endolymphatic space of the cochlea (guinea pig). Am J Physiol. 1958;194:396-402.

43. Sterkers O, Ferrary E, Amiel C. Inter- and intracompartmental osmotic gradients within the rat cochlea. Am J Physiol. 1984;247:F602-6.

44. Huang T, Cheng AG, Stupak H, Liu W, Kim A, Staecker H, et al. Oxidative stress-induced apoptosis of cochlear sensory cells: otoprotective strategies. Int J Dev Neurosci. 2000;18:259-70.

45. Yehoash R. Cochlear pathology, sensory cell death and regeneration. Br Med Bull. 2002;63:25-38.

46. Ohtaki H, Nakamachi T, Dohi K, Shioda S. Role of PACAP in ischemic neural death. J Mol Neurosci. 2008;36:16-25.

47. Reglodi D, Fabian ZS, Tamas A, Lubics A, Szeberenyi J, Alexy T, et al. Effects of PACAP on in vitro and in vivo neuronal cell death, platelet aggregation, and production of reactive oxygen radicals. Regul Pept. 2004;123:51-9.

48. Reglodi D, Kiss P, Lubics A, Tamas A. Review on the protective effects of PACAP in models of neurodegenerative diseases in vitro and in vivo. Curr Pharm Des. 2011;17:962-72.

49. Kopke RD, Liu W, Gabaiyadeh R, Jacono A, Feghali J, Spray D, et al. Use of organotypic cultures of Corti's organ to study the protective effects of antioxidant molecules on cisplatininduced damage of auditory hair cells. Am J Otol. 1997;18:559-71.

50. Seidman MD, Vivek P. Intratympanic treatment of hearing loss with novel and traditional agents. Otolaryngol Clin North Am. 2004;37:973-90.

51. Cheng AG, Cunningham LL, Rubel EW. Hair cell death in the avian basilar papilla: characterization of the in vitro model and caspase activation. J Assoc Res Otolaryngol. 2003;4:91-105.

52. Hirose K, Westrum LE, Stone JS, Zirpel L, Rubel EW. Dynamic studies of ototoxicity in mature avian auditory epithelium. Ann N Y Acad Sci. 1999;884:389-409. 
53. Matsui JI, Gale JE, Warchol ME. Critical signaling events during the aminoglycoside-induced death of sensory hair cells in vitro. J Neurobiol. 2004;61:250-66.

54. Dehne N, Lautermann J, ten Cate WJ, Rauen U, de Grott H. In vitro effects of hydrogen peroxide on the cochlear neurosensory epithelium of guinea pig. Hear Res. 2000;143:162-70.

55. Dejda A, Jolivel V, Bourgault S, Seaborn T, Fournier A, Vaudry H, et al. Inhibitory effect of PACAP on caspase activity in neuronal apoptosis: a better understanding towards therapeutic applications in neurodegenerative diseases. J Mol Neurosci. 2008;36:26-37.

56. Pantaloni C, Brabet P, Bilanges B, Dumuis A, Houssami S, Spengler D, et al. Alternative splicing in the N-terminal extracellular domain of the pituitary adenylate cyclaseactivating polypeptide (PACAP) receptor modulates receptor selectivity and relative potencies of PACAP-27 and PACAP-38 in phospholipase C activation. J Biol Chem. 1996;271:22146-51.

57. Ikeda R, Nakaya K, Oshima T, Kawase T, Kobayashi T. Calcium concentration in cochlear endolymph after vestibular labyrinth injury. Neuroreport. 2010;21:651-5.

58. Ikeda K, Kusakari J, Takasaka T. Ionic changes in cochlear endolymph of the guinea pig induced by acoustic injury. Hear Res. 1988;32:103-10.

59. Lendvai B, Halmos GB, Polony G, Kapocsi J, Horvath T, Aller M, et al. Chemical neuroprotection in the cochlea: the modulation of dopamine release from lateral olivocochlear efferents. Neurochem Int. 2011;59:150-8.

60. Li Y, Ding D, Jiang H, Fu Y, Salvi R. Co-administration of cisplatin and furosemide causes rapid and massive loss of cochlear hair cells in mice. Neurotox Res. 2011;20:307-19.

61. Salt AN, DeMott J. Endolymph calcium increases with time after surgical induction of hydrops in guinea-pigs. Hear Res. 1994;74:115-21.

62. Orrenius S, McCabe Jr MJ, Nicotera P. Ca(2+)-dependent mechanisms of cytotoxicity and programmed cell death. Toxicol Lett. 1992;64-65:357-64.

63. Trump BF, Berezesky IK. The role of altered [Ca2+]i regulation in apoptosis, oncosis, and necrosis. Biochim Biophys Acta. 1996;1313:173-8.

64. Gilbert RJ, Pothoulakis C, LaMont JT, Yakubovich M. Clostridium difficile toxin B activates calcium influx required for actin disassembly during cytotoxicity. Am J Physiol. 1995;268:G487-95.

65. Hackney CM, Mahendrasingam S, Penn A, Fettiplace R. The concentrations of calcium buffering proteins in mammalian cochlear hair cells. J Neurosci. 2005;25:7867-75.

66. Heizmann CW. Calcium-binding proteins: basic concepts and clinical implications. Gen Physiol Biophys. 1992;11:411-25.

67. Iacopino A, Christakos S, German D, Sonsalla PK, Altar CA. Calbindin-D28K-containing neurons in animal models of neurodegeneration:possible protection from excitotoxicity. Brain Res Mol Brain Res. 1992;13:251-61.

68. Idrizbegovic E, Salman H, Niu X, Canlon B. Presbyacusis and calcium-binding protein immunoreactivity in the cochlear nucleus of BALB/c mice. Hear Res. 2006;216-17:198-206.

69. Rybak LP, Whitworth CA. Ototoxicity: therapeutic opportunities. Drug Discov Today. 2005; 10:1313-21.

70. Poirrier AL, Van den Ackerveken P, Kim TS, Vandenbosch R, Nguyen L, Lefebvre PP, et al. Ototoxic drugs: difference in sensitivity between mice and guinea pigs. Toxicol Lett. 2010;193:41-9.

71. Huth ME, Ricci AJ, Cheng AG. Mechanisms of aminoglycoside ototoxicity and targets of hair cell protection. Int J Otolaryngol. 2011;937861.

72. Tombal B, Denmeade SR, Gillis JM, Isaacs JT. A supramicromolar elevation of intracellular free calcium $([\mathrm{Ca}(2+)](\mathrm{i}))$ is consistently required to induce the execution phase of apoptosis. Cell Death Differ. 2002;9:561-73.

73. Vaudry D, Falluel-Morel A, Bourgault A, Basille M, Burel D, Wurtz O, et al. Pituitary adenylate cyclase activating polypeptide and its receptors: 20 years after the discovery. Pharm Rev. 2009;61:283-357.

74. Dong Y, Tang TS, Lu CL, He C, Dong JB, Huang XY, et al. Pituitary adenylate cyclase activating polypeptide ameliorates the damage and inhibits the increase of intracellular calcium concentration in cultured hippocampal neurons induced by glutamate. Sheng Li Xue Bao. 2000;52:402-6. 